\title{
Access to print literacy for children and young people with visual impairment: findings from a review of literature
}

Graeme Douglas $^{\mathrm{a} *}$, Mike McLinden ${ }^{\mathrm{a}}$, Steve McCall ${ }^{\mathrm{a}}$, Sue Pavey ${ }^{\mathrm{a}}$, Jean Ware ${ }^{\mathrm{b}}$ and Ann Marie Farrell ${ }^{\mathrm{C}}$

${ }^{a}$ Visual Impairment Centre for Teaching and Research (VICTAR), School of Education, University of Birmingham, Birmingham, UK; ${ }^{b}$ College of Arts Education and Humanities, Bangor University, Bangor, Wales; 'St Patrick's College, Dublin, Ireland

(Received 17 August 2010; final version received 26 October 2010)

This article presents a selection of findings from a literature review of best practice models and outcomes in the education of visually impaired children. The review suggested that a key focus of research in this area has been upon the concept of 'access', particularly with regards to barriers children with visual impairment face in accessing visual information. Given the broad scope of the literature review, we focus upon access to print literacy as an illustrative example. The potential impact of reduced access to the curriculum and the effectiveness of teaching approaches adopted to reduce these barriers are presented. The relative merits of two approaches to improve access are contrasted: providing children with accessible material in their preferred medium (e.g., large print), and teaching children 'access skills' (including the use of technology). There is evidence to show that both approaches are important, but teaching children access skills has important longerterm benefits for visually impaired children and young people. In spite of this evidence, it appears that this approach to teaching may often be neglected. Links are made with other areas of the curriculum to illustrate that this dual view of access is a helpful way of conceptualising the broader educational needs of visually impaired pupils.

Keywords: visual impairment; children; literature review; access; curriculum; literacy

\section{Introduction}

\section{Background}

This article draws upon a recent literature review of evidence of best practice models and outcomes in the education of visually impaired children (Douglas et al. 2009). The review was commissioned by the National Council for Special Education, Ireland. The terms of reference for the review emphasised that it should identify evidence-based outcomes for children as well as offer recommendations and implications for the Irish education and health systems. Given the wide ranging nature of the review, this article is primarily concerned with outcomes relating to 'access to print literacy' which is drawn upon as an illustrative example. An accompanying article in this issue of the journal describes how the review findings were applied to a particular service and policy context.

*Corresponding author. Email: g.g.a.douglas@bham.ac.uk 


\section{Method}

The approach taken to the literature review can be summarised in the three stages described in the following sub-sections (for a more detailed description of the review method including details of databases accessed and search terms used see Douglas et al. [2009]).

\section{Agreeing a broad topic framework for the literature}

The framework divided the literature into three broad themes (and linked subtopics), which were drawn from general texts in the field of visual impairment and education (Arter et al. 1999; Holbrook and Koenig 2000; Koenig and Holbrook 2000; Mason et al. 1997) and the reviewers' interpretation of these. The three themes were:

(1) Legislation, policy, and service delivery

(2) Classroom and the curriculum

(3) Additional curriculum needs

To be included in the review, studies had to be empirically based in some way. That is, they needed to be based on a formal study that involved the systematic collection of data rather than simply the author's opinion (though data could have included a collection of the opinions of, for example, a group of professionals).

\section{Stage 1 of the review}

Much of the empirical literature in this field has been published in a number of specific specialist journals (including three international journals: the British Journal of Visual Impairment, Journal of Visual Impairment and Blindness, and RE:view). The team had access to these journals through their own database, which contained summaries of more than 2000 research articles.

As stage 1 of the review was completed, the team appraised the identified literature in relation to the central purpose of the review. At this point some of the topics of the review were identified as central and were developed further (those related to 'classroom and the curriculum' and 'additional curriculum needs'), while others were identified as providing useful context only and in the main were not empirically based (those related to 'legislation, policy, and service delivery').

Stage 2 of the review (broader systematic searches of electronic databases)

Stage 2 of the reviewing process involved broader systematic searches of electronic databases (such as ERIC) to confirm, add to and (possibly) challenge and 'test' the initial analyses. Not surprisingly, stage 2 overlapped considerably with stage 1; nevertheless, it did identify some additional useful sources.

\section{Broad outcomes of the literature review}

A number of factors serve as the main drivers in the formulation of educational policy. These include research outcomes and recommendations, government initiatives, and 
international policies. A helpful illustration of these drivers is provided by the policy shift towards the educational placement of children with disability in mainstream schools observed in many countries. An important driver of these policy developments is the shift towards broad social inclusion throughout society as a whole. This 'societal shift' is reflected in (and driven by) national government and international policies (for example the Salamanca Statement on Special Needs Education [United Nations Educational, Scientific and Cultural Organization (UNESCO) 1994]). It is often 'below' these higher-level policy contexts that educational research operates. Perhaps not surprisingly, therefore, the literature review identified no substantial research in the area of visual impairment education that seeks to compare empirically the efficacy of different broad educational policies. As an example, in relation to educational placement no empirical evidence could be located to show that one type of placement is more effective in meeting the needs of children with visual impairment than another.

Educational research in the area of visual impairment also appears to have its own traditions. For example, in a review of pedagogy and visual impairment education Douglas and McLinden (2005) argue that a key research emphasis in the past has been on the concept of 'access'. The reason for this focus seems to be a widely-held view that a principal barrier faced by visually impaired children is 'access' to visual information (i.e., as a direct result of having reduced or no vision). In the context of education, therefore, an important role of an educator is to identify appropriate ways of reducing this potential barrier in their teaching. Two significant educational strategies that have been adopted are the enhancement of visual information (for example through the use of large print), and the presentation of visual information in alternative formats (such as auditory or tactual). Therefore, an important focus of research in visual impairment education has been on developing and evaluating these approaches to reducing barriers to access, i.e., researchers and practitioners describe approaches they adopt in order to provide visually impaired students with improved access to information drawing on either enhanced or alternative presentations of visual information. An implicit comparator of this research design is that without the educational approach, 'access' to information for the child would not be possible (or would be severely compromised). The implication of this research design is that studies in the field of visual impairment generally do not have an explicit comparative design.

The literature review demonstrated that this broad research design provides much of the empirical evidence in the field of visual impairment. Examples in relation to curriculum access include case studies describing 'modifications' made to materials; research studies reporting on how information and communication technology (ICT) has been used to gain access to information; and research describing children's access to literacy through print or Braille. As a consequence, there is limited evidence in the literature concerning the relative merits of alternative teaching approaches through the use of a comparative research design that investigates, for example, whether one type of teaching strategy is more effective than another.

A key outcome to emerge from the review of literature, therefore, is that the predominant research design seeks to demonstrate improved 'access' as an outcome of a particular educational intervention rather than to compare different types of educational approaches, models or placement. This tradition of research is different from that in some other disciplines within special education in which there is a continuing debate about how best to teach children with given disabilities. The field 
of autistic spectrum disorders (ASD) serves as a useful illustration. In that field there are different views about which educational interventions work most effectively with children with ASD (see, for example, a related review of literature by Parsons et al. [2009]).

\section{Specific recommendations and implications}

The review made a distinction between literature concerned with 'classroom and the curriculum' and 'additional curriculum needs'. As noted earlier, this distinction is in keeping with a number of commentators in the literature, who distinguish between visually impaired children's access to the 'mainstream' (or 'core') curriculum and their access to the 'additional' curriculum. Precisely how curriculum areas should be split between the two is debatable but the general distinction is useful in organising the literature and in service design and delivery.

The review provided strong evidence to demonstrate that children with visual impairment have particular teaching and curriculum needs, and presented nine evidence-based recommendations. With regard to teaching and access to the mainstream curriculum, children with visual impairment require modified educational provision to enable them to gain access to the curriculum. The review presented evidence of this in relation to:

- An assessment of their learning needs

- The teaching strategies adopted

- Approaches to formal examinations

- Approaches in relation to the teaching of literacy (including print and Braille).

With regard to the additional curriculum, there is evidence that children with visual impairment require additional intervention in order to develop skills in the following areas:

- Mobility and independence

- Social and emotional development

- The use of ICT

- Low vision.

The review also considered the implications of the literature review for Ireland. These implications for policymakers and classroom practice are discussed in an accompanying paper in this issue of the journal. The implications drew upon the evidence-based recommendations, as well as literature related to international and Irish legislation and policy.

\section{Aims of the paper}

Given space restrictions, rather than providing an overview of the entire review we focus upon the following:

- The application of the concept of access in relation to print literacy and visual impairment. 
- The links between access to print literacy and other relevant areas of the literature review (and how the concept of access can be applied to education and visual impairment more broadly).

\section{Print literacy}

For the purposes of this paper, the literature relating to print literacy is categorised under four related themes, each with a connection to 'access':

(1) Access to print and delays to reading development

(2) Improving access through changing print format

(3) Access and the role of technology

(4) 'Teaching access skills' versus 'providing accessible material'.

A summary of literature identified within the review is provided under each of these themes.

\section{Access to print and delays to reading development}

The first theme considers visually impaired children's access to print through a synthesis of literature related to reading performance. As examples of this literature, Douglas et al. (2002) and Hill et al. (2005) observed delays in speed, accuracy and comprehension of print reading among British children with low vision. They made a distinction between developmental delays in reading and difficulties in access to text, arguing that long-term difficulty in accessing text leads to developmental delays. Others (most notably a series of studies by Gompel and colleagues, e.g., Gompel et al. [2004]) found that, despite their lower reading speed on a reading-comprehension task, the children with low vision comprehended texts at least as well as sighted children. Nevertheless, Gompel et al. (2002) noted that decoding (comparable to Douglas et al.'s 'reading accuracy') was also delayed compared with normally sighted children.

There are mixed findings in the analysis of print reading errors: Douglas et al. (2004) and Cornelissen (1991) noted that children with low vision made particular types of errors (e.g., a greater tendency to make substitution errors), while Bosman et al. (2006) and Corley and Pring (1993) did not find this. In spite of these inconsistent results there is consensus that there are trade-offs between reading accuracy, speed, and comprehension - as a result of the increased effort required of children with visual impairment to access and decode print, their accuracy is poorer and reading takes longer, and comprehension probably drops.

In summary then, the literature suggests that children with visual impairment tend to have poorer print reading performance than their sighted peers because (1) print is harder for them to access; and (2) the implications of long-term difficulties accessing print lead to developmental delays.

\section{Improving access through changing print format}

The second theme in the literature related to methods of improving access through modification of print format. A number of studies have investigated various aspects of 
print format, e.g., Buultjens et al. (1999) (print size and font) and McLeish (2007) (letter-spacing). Such studies make some useful recommendations as to the best format for the study sample (for example Buultjens et al. [1999] described 24-point size and font Helvetica or Arial as the most 'generally accessible' of those they tested).

However, an important observation is related to individual differences between participants, i.e., the different access requirements of individual children. It is unsurprising, then, that a review by Russell-Minda et al. (2007) of research evidence on the effects of the characteristics of typefaces on the legibility of text for adult readers with low vision identified no consistent findings. This lack of clarity (i.e., a failure to identify a 'one format fits all' solution) leads to tensions with some strategies for access.

An alternative approach that has been explored, therefore, is to find methods of understanding an individual's needs. As examples, Hall Lueck et al. (2003) and Bailey et al. (2003) offer detailed descriptions of how to determine print size requirements for a low-vision reader. This involves measuring reading speed for different print sizes to determine the smallest size for the maximum speed (the 'critical print size'). However, such an assessment must account for preferred (and comfortable or sustainable) viewing distance, different tasks (for example sustained reading versus shortterm reading), and the individual's reading ability. Such an analysis should also then consider the mechanism by which print size is achieved (i.e., by enlarged hardcopy print or standard print with LVAs/technology, or a combination of the two).

In summary then, the literature suggests that optimal print size should be established for students on an individual basis, but that this is independent of how this print size is achieved (e.g., by enlarging print or through the use of technology).

\section{Access and the role of technology}

The third theme also related to interventions that seek to improve access to print, although the focus was upon the use of technology including for example, low vision aids (LVAs) and closed-circuit television (CCTV). LVAs, CCTV and electronic magnification (most notably computer-based magnification software) are extensively cited in the literature as useful techniques for enabling low-vision print readers to establish optimal print size (and, therefore, to access print efficiently). Similarly, good-quality task lighting is also commonly cited as a key method of improving reading efficiency (e.g., Foss and Valberg [2004] in relation to older people).

Papadopoulos and Goudiras (2005) provide an overview of screen magnification software and its benefits. Similarly, Corn et al. (2003) offer an overview of the literature in relation to LVAs and provide an analysis of cost-effectiveness that supports the use of LVAs over the provision of large-print hard copy material. They argue that the use of LVAs provides a more 'elegant strategy' than large print, in that teaching students to use LVAs means they can have independent access to standard print without having to rely on other people to prepare material for them. A number of empirical studies provide supporting evidence that LVAs can be used successfully by children to read efficiently, given training and practice. As an example, Corn et al. (2002) present a study showing that children who received optical devices increased their silent reading speeds and comprehension rates. Other studies offer similar evidence (Smith and Erin 2002).

Of particular relevance to this theme is a review of eight research studies comparing LVAs plus normal print with enlarged print (Lussenhop and Corn 2002). Their 
review concluded 'that reading standard print with optical devices is as effective a literacy medium as large print - and perhaps a more effective one' (67). The authors note that LVAs are not always the appropriate solution, but even so they feel it is important for teachers and students to re-examine 'assumptions and traditional reliance on large print' (68). This call to re-examine practice chimes with the work of Barraga (1990) some ten years earlier, which stated that:

...evidence is conclusive that using optical devices with regular print materials is just as efficient, no more fatiguing, increases accessibility, and is far more cost effective than large print. Nevertheless, large-print books continue to be used long after they are actually needed. (15)

It would be simplistic to argue that the use of magnifying technology (whether and LVA or a computer screen) is always a better option that hardcopy enlarged print. There may be particular tasks which are better suited to enlarged print (e.g., accessing complex tabular information or diagrams), or at particular times with particular students when the use of LVAs may be difficult (e.g., students with rapidly deteriorating vision, or perhaps some students with complex needs). Nevertheless, empirical evidence suggests that the use of magnifying technology is generally more effective than hardcopy enlarged print for accessing print by children with visual impairment. This general position is reflected in pedagogical texts in the field of visual impairment and education (Mason et al. 1997; Corn and Koenig 1996). It is also reflected in the findings from Corn and Koenig's (2002) application of the 'Delphi method' to gain consensus on approaches to teaching literacy to children with low vision from forty practitioners with expertise in that area. The study divided literacy and low vision into 11 areas (from emergent through to advanced literacy skills) and identifies the use of technology and optical devices amongst the teaching approaches that should be adopted by practitioners.

\section{'Teaching access skills' versus 'providing accessible material'}

A study by Mason (1999) examined the reasons for the low take-up and use of LVAs by pupils with a visual impairment in UK mainstream secondary schools. The study usefully illustrates an observed challenge of using LVAs in practice. A key finding of the study was that peer pressure from other pupils was a major reason cited by children with visual impairment for not using an LVA. Mason (1999) also noted that not all teachers had clearly defined criteria for judging whether LVAs were being used effectively. Similarly, a later study in the UK (Franklin et al. 2001) reported the low takeup of LVAs among children and young people with a visual impairment with participants reporting that LVAs made them feel 'different' (112).

Although not included in the literature review, it is useful to make reference to the findings of a recent survey of 21 teaching services carried out by the authors in England and Wales. As shown in Table 1, this illustrates the range of preferred reading formats these services currently provide with over $30 \%$ of supported pupils reported to prefer font size 20 point or greater.

The studies reported earlier offer a useful illustration of two apparently contrasting strategies that are reported in the literature in order to provide visually impaired pupils with 'access' to print literacy. On the one hand, empirical research and published 'expert views' (both in published texts and as captured in Corn and Koenig's [2002] 
Table 1. Visually impaired students' (aged 13-16 years) preferred reading formats as reported by 21 education services in England and Wales ( $n=287$ pupils).

\begin{tabular}{lcr}
\hline Preferred reading format & Total $(n)$ & Percentage \\
\hline 12 point & 57 & $19.86 \%$ \\
$14-18$ point & 113 & $39.37 \%$ \\
$20-24$ point & 69 & $24.04 \%$ \\
$>24$ point & 27 & $9.41 \%$ \\
Braille & 18 & $6.27 \%$ \\
Electronic & 3 & $1.05 \%$ \\
Total & 287 & $100.00 \%$ \\
\hline
\end{tabular}

study) recommend what can be described as a 'teaching access skills' approach. Within this approach visually impaired pupils are provided with instruction in the use of technology in order to access print. The literature reported previously focuses on LVAs, but a similar corpus exists illustrating the use of computer-based technology in order to access print (Papadopoulos and Goudiras 2005). On the other hand, there is evidence that practitioners commonly emphasise 'providing accessible material' to a child, in which those responsible for teaching the child provide material in a predetermined format (e.g., a large-print book in font size 20 point). There is evidence to suggest that part of the reason for this approach is that pupils with visual impairment do not want to appear different to their peers (and as such may not want to use an LVA). However, there is also a broader policy dimension to be considered in relation to the term 'access' that reflects recent disability legislation. As an example taken from the USA, Frank (2000) argues that people have a 'right' to enlarged ('accessible') print formats under the Americans with Disabilities Act. Taken to its logical conclusion this 'right' can imply a school is required to provide a visually impaired child with their learning media in a pre-determined format. As noted earlier, however, there is evidence in the literature to suggest that LVAs can offer an appropriate alternative and, crucially, can serve to lessen pupils' reliance on others to produce their materials, i.e. can encourage independence.

This short summary of literature in relation to print literacy highlights an interesting tension between educational approaches and contemporary policy directions in relation to disability. Arguably the former would emphasise teaching students access skills (i.e., how to use LVAs and other technology), while the latter would emphasise providing materials to optimise access (i.e., the provision of bespoke hardcopy enlarged print).

\section{Connections with other aspects of the review}

The analysis of research literature in relation to print literacy has highlighted the use of the concept of 'access' in relation to education and visual impairment. We also argued that different interpretations of the term 'access' could lead to the use of different educational approaches. In this section we consider whether these differences can be applied (or, indeed, are observed) in other areas of the curriculum. Two examples are presented: (1) the use of computer technology; and (2) access to assessment and examinations. 


\section{Example 1: computer technology}

Computer technology has become almost ubiquitous in the education of visually impaired children, as it provides access to information that would otherwise be difficult or even impossible to obtain (for example screen reading software, screen magnification software, Braille translation software). An important emphasis in the literature in relation to computer technology is on the presentation and control opportunities that technology affords that make it particularly valuable in the education of visually impaired people. For example, computers can enhance visual presentations (e.g., backlit screen displays of large text in a range of colour combinations) or provide alternative presentations (e.g., speech or Braille output of screen-based text).

These access qualities of technology are reflected in much of the research that has been carried out in the area, most notably descriptions and case studies of the use of computers and related equipment. Examples of such studies include: Lancioni (2007), who described the use of switches by children with multiple disabilities and visual impairment (MDVI); Douglas et al. (1994), who described the teaching of touchtyping; Sales et al. (2006), who described screen magnification software; Mioduser et al. (2000), who described software for developing spelling; Schweigert and Rowland (1992), who presented case studies of using augmentative and alternative communications (AAC) technology successfully with children with MDVI; and Jones (2004), who described teaching both partially sighted and blind children Internet access skills.

In this context, Douglas (2001) made a distinction between 'educational technology' and 'access technology' (often called 'enabling' or 'assistive' technology). The former is described as having an explicit educational aim (e.g., software for practicing spelling), while the latter is used in conjunction with mainstream software in order to provide 'access' to the underlying functions (e.g., magnification software used in conjunction with a word processing application). In practice, educational and access technology, overlap to some extent but there are parallels here with the distinction made between 'accessible material' and 'access skills'. Some educational technology is specifically designed or adapted for visually impaired students (as in the case of the touch typing software example earlier), and this can be likened to accessible material. In contrast, access technology can be likened to 'access skills' because once trained in the use of these applications the user is able to access a range of mainstream applications. The literature presents evidence that both approaches to using technology are valuable.

Linked to this is literature that highlights the importance of technology skills in later life. Trief and Feeney (2003) surveyed visually impaired students who had successfully completed college courses about the importance of various competencies acquired before going to college: computer, assistive technology and keyboarding skills were all emphasised as important. In a large-scale survey of visually impaired people Douglas, Corcoran, and Pavey (2007) found that adults who used technology were more likely to be in employment.

Given that technology skills (as part of an additional curriculum) are emphasised as providing a means for visually impaired children to access the curriculum, it is hardly surprising that the literature contains examples of work in relation to teachers' training needs in this area (Murphy et al. 2008; Abner and Lahm 2002).

\section{Example 2: assessment and examinations}

The formal assessment of children through public examinations is a central feature of most education systems. Nevertheless, standard examination formats and procedures 
may present barriers to visually impaired pupils, which mean that they cannot demonstrate their abilities under standard examination conditions. While there appears to be no systematic international analysis of how examination procedures work for visually impaired students, there was some useful literature in relation to systems in the UK. Cobb (2008) offers the most substantial overview of the system in England and Wales (as well as a history of its development). The central mechanism is 'access arrangements', whereby examination 'modification' or 'enlargement' is requested from examination boards for particular arrangements for individual students before their examination. However, a limited choice of modifications is available.

Cobb's (2008) work has shown that the present system in England for large-print modification does not work very well for GCSEs (examinations at the age of 16) and appears to be particularly problematic when offered to mainstream pupils. One of the problems identified was that the choices of examination format (in effect large type, of 18 or 24 point, or Braille) are inadequate for meeting the needs of the pupils. Arguably, the examinations Cobb described were inadequately accessible on two counts: firstly, the limited choices of presentation formats were not as students wanted it, i.e. the examination boards were not 'providing accessible material'; secondly, the students had not been taught the necessary 'access skills' to access the examination.

Another way of expressing this is that the examinations were not presented in a format which enabled students to use their access skills (e.g., if examinations were available electronically). Miller et al. (2005) reviewed the literature on accessible curricula, qualifications, and assessment. The review was linked to disability generally, though it did draw on examples related to visual impairment. The authors made a distinction between 'access arrangements' and 'universal design': the former means that the adjustments are 'post hoc', while the latter means that adjustments are built into the design of the assessment rather than added on later. Papadopoulos and Goudiras (2004) and Nisbet (2007) have explored electronic access to examinations and this work has resonance with a 'universal design' approach.

\section{Discussion}

The commissioned literature review aimed to identify evidence of best practice models and outcomes in the education of blind and visually impaired children. In this article we present some of the literature in relation to the teaching of print literacy to children with low vision. Perhaps the most direct implication of the literature is that, given the particular challenges children with visual impairment face in accessing print literacy, specialist services with responsibility for supporting their education should ensure that a child's optimal print size is established as part of a functional visual assessment. It was also argued that whil teaching children with resources in large print (i.e., large text presented on paper) is a useful technique for providing optimal print size in some circumstances, priority should be given to teaching children to use LVAs and other technology effectively to optimise their access to print. In itself, we believe this is a useful recommendation that appears to challenge common classroom practice emphasising the use of large print over LVAs; for examples, see Mason (1999) and Table 1 for the UK, and Lussenhop and Corn (2002) for the USA.

Nevertheless, in this article we have tried to use the example of print literacy as an illustration of a more general issue to emerge from the literature review regarding the concept of 'access' and providing children and young people with visual impairment 'access' to education. Perhaps more accurately, the literature review re-affirmed the 
importance of access as a key concept as it has been highlighted by a range of authors (e.g., Mason et al. [1997] entitled their book Access to education for children and young people). However, 'access' is a deceptively complex and multi-levelled term. In the article we make a distinction between 'providing accessible material' and 'teaching access skills'. Both are undoubtedly important and worth considering in turn.

'Providing accessible material' can be thought of as being focussed upon the 'here and now' of a child's life. Material preparation and teaching strategies are vital to enable visually impaired children and young people to have access to information, curriculum materials, assessment, social and spatial environments and the myriad other aspects of educational life. Relatively contemporary policy in relation to disability in many countries commonly offers the legislative framework in which the provision of accessible materials should happen through requirements to make 'reasonable adjustments' (UK) or take 'reasonable measures' (Ireland). Examples of these policies are the Americans with Disabilities Act in the USA, the Disability Discrimination Act in the UK, and the Disability Act in Ireland.

'Teaching access skills' is also a critical part of educational intervention. It can be thought of as taking a 'longer-term' developmental view of visually impaired children's education by teaching skills which will enable them to gain access to information and curriculum materials for themselves, and to navigate independently social and spatial environments. Arguably, this approach also provides students with the skills they need to study and work independently in later life. Nevertheless, evidence suggests that teaching strategies adopted in some education services in the UK and USA may focus upon providing accessible material at the expense of teaching students access skills (at least in the area of print literacy).

The article also draws upon two other examples to illustrate how this 'dual' view of access can be usefully applied in other contexts. In the case of the first example (the use of ICT in the education of visually impaired children and young people), this appears quite straightforward. There are many examples in the literature in which computers provide access to educational information through enhanced or alternative presentations. (It is not the topic of this paper, but there are examples when computer software is inaccessible to visually impaired people but it could and should be accessible with reasonable adjustment and design by the manufacturers.) It was also emphasised that teaching visually impaired students to use computers to access information independently through the use of 'access technology' is critical (e.g., screen readers, magnification software, touch typing).

We would argue that similar language could be applied to other aspects of the literature review in relation to the education of children and young people with visual impairment. For example: Braille and Moon offer accessible formats for people with severe visual impairment - the production of these materials must be coupled with teaching students how to read these formats; young people with visual impairment often find it hard to navigate complex spatial environments like a school - modifications to the environment and offering sighted guides must be coupled with teaching students mobility skills.

The second example (access to assessment and examinations) arguably offers a different lesson. Drawing on the situation in England as an example, there is evidence that some students appear to find available access options in examinations inadequate. The examination presentation options available for students with low vision are limited and, therefore, some students (e.g., those who do not use LVAs and want a 
font size greater than 24 point) find access difficult. This is a very particular example, but we argue it highlights the challenges faced by visually impaired students when there is a disconnection between the access approaches adopted by different parts of the education process (in this case a disconnection between classroom practice and examination board policy in relation to access and modification).

\section{Conclusion}

In conclusion, we would argue that when considering access to education for visually impaired students a distinction between the provision of 'accessible materials' and 'teaching access skills' is useful and has an empirical basis. This distinction also has a philosophical rationale that emphasises both society's responsibility to make things accessible and society's role in teaching young people to be independent. Finding the right balance, or blend, of these different approaches is a key challenge for those involved in ensuring curriculum access is appropriate for individual children with visual impairment. The research literature presented in this review provides useful evidence that can guide educators in meeting this challenge.

\section{Acknowledgements}

We are grateful to the National Council for Special Education (NCSE) for providing funding to undertake this review. We also thank members of the NCSE and the anonymous reviewer for their helpful comments on drafts of the report.

\section{References}

Abner, G.H., and E.A. Lahm. 2002. Implementation of assistive technology with students who are visually impaired: Teachers' readiness. Journal of Visual Impairment and Blindness 96, no. 2: 98-105.

Arter, C.A., H.L. Mason, S. McCall, M. McLinden, and J. Stone. 1999. Children with visual impairments in mainstream settings. London: David Fulton Publishers.

Bailey, I.L., A. Hall Lueck, R.B. Greer, K. Mon Tuan, V.M. Bailey, and H.G. Dornbusch. 2003. Understanding the relationships between print size and reading in low vision. Journal of Visual Impairment and Blindness 9, no. 76: 325-34.

Barraga, N.C. 1990. Infusion of research and practice into personnel preparation. Peabody Journal of Education 67, no. 2: 10-21.

Bosman, A.M.T., G. Marjolein, P.J. Vervloed Mathijs, and H.J. van Bon Wim. 2006. Low vision affects the reading process quantitatively but not qualitatively. The Journal of Special Education 39, no. 4: 208-19.

Buultjens, M., S. Aitken, and J.C. Kevin Ravenscroft. 1999. Size counts: The significance of size, font and style of print for readers with low vision sitting examinations. British Journal of Visual Impairment 17, no. 1: 5-10.

Cobb, R.A. 2008. Exploring systems for the provision of modified large print examination papers to partially sighted candidates in England and Wales. MPhil diss., Univ. Birmingham.

Corley, G., and L. Pring. 1993. The oral reading errors of partially sighted children. British Journal of Visual Impairment 11, no. 1: 24-7.

Corn, A.L., and A.J. Koenig. 2002. Literacy for students with low vision: A framework for delivering instruction. Journal of Visual Impairment and Blindness 96, no. 5: 305-21.

Corn, A.L., J.K. Bell, E. Andersen, C. Bachofer, R.T. Jose, and A. Perez. 2003. Providing access to the visual environment: A model of low vision services for children. Journal of Visual Impairment and Blindness 97, no 5: 261-72.

Corn, A.L., and A.J. Koenig, Eds. 1996. Foundations of low vision: Clinical and functional perspectives. New York: AFB Press. 
Corn, A.L., R.S. Wall, R.T. Jose, J.K. Bell, K. Wilcox, and A. Perez. 2002. An initial study of reading and comprehension rates for students who received optical devices. Journal of Visual Impairment and Blindness 96, no. 5: 322-34.

Cornelissen, P. 1991. What children see affects how they read. Developmental Medicine and Child Neurology 33, no. 9: 755-62.

Douglas, G. 2001. ICT, education, and visual impairment. British Journal of Educational Technology 32, no. 3: 353-64.

Douglas, G., C. Corcoran, and S. Pavey. 2007. The role of the WHO ICF as a framework to interpret barriers and to inclusion: Visually impaired people's views and experiences of personal computers. British Journal of Visual Impairment 25, no. 1: 32-50.

Douglas, G., A. Gamble, and E. Hill. 1994. Evaluating touch typing programs. Visability 12: $31-2$.

Douglas, G., M. Grimley, E. Hill, R. Long, and M. Tobin. 2002. The use of the NARA for assessing the reading ability of children with low vision. British Journal of Visual Impairment 20, no. 2: 69-75.

Douglas, G., M. Grimley, M. McLinden, and L. Watson. 2004. Reading errors made by children with low vision. Ophthalmic and physiological optics 24, no. 4: 319-22.

Douglas, G., and M. McLinden. 2005. Visual impairment. In: Special teaching for special children? Pedagogies for inclusion, ed. A. Lewis and B. Norwich, 26-40. Milton Keynes, UK: Open University Press.

Douglas, G., S. McCall, M. McLinden, S. Pavey, J. Ware, and A.M. Farrell. 2009. International review of the literature of evidence of best practice models and outcomes in the education of blind and visually impaired children. National Council for Special Education, Ireland. http://www.ncse.ie/uploads/1/Seminar_abstract_blind_review_Dec_09.pdf

Foss, P., and A. Valberg. 2004. Lighting needs and lighting comfort during reading with age-related macular degeneration. Journal of Visual Impairment \& Blindness 98, no. 7: 389-409.

Fraiberg, S. 1977. Insights from the blind. London: Souvenir Press.

Frank, J.J. 2000. Requests by persons with visual impairments for large-print accommodations. Journal of Visual Impairment and Blindness 94, no. 11: 716-9.

Franklin, A., S. Keil, K. Crofts, and I. Cole-Hamilton. 2001. Shaping the future: The experiences of blind and partially sighted children and young people in the UK. Research report 2: The educational experiences of 5 to 16 year-old blind and partially sighted children and young people. London: RNIB.

Gompel, M., W.H.J. van Bon, R. Schreuder, and J.J.M. Adriaansen. 2002. Reading and spelling competence of Dutch children with low vision. Journal of Visual Impairment and Blindness 96, no. 6: 435-47.

Gompel, M., W.H.J. van Bon, and R. Schreuder. 2004, Reading by children with low vision. Journal of Visual Impairment and Blindness 98, no. 2: 77-89.

Hall Lueck, A., I.L. Bailey, R.B. Greer, K. Mon Tuan, V.M. Bailey, and H.G. Dornbusch. 2003. Exploring print-size requirements and reading for students with low vision. Journal of Visual Impairment and Blindness 97, no. 6: 335-54.

Hill, E., R. Long, G. Douglas, M. Tobin, and M. Grimley. 2005. Neale Analysis or Reading Ability for readers with low vision: A supplementary manual to aid the assessment of partially sighted pupil's reading using the Neale analysis of reading ability (NARA). University of Birmingham.

Holbrook, M.C., and A. Koenig. 2000. History and theory of teaching children and youths with visual impairments. Vol. 1 of Foundations of education. 2nd ed. New York: AFB.

Jones, R. 2004. Teaching Internet skills to pupils with a severe visual impairment. British Journal of Visual Impairment 22, no. 3: 84-8.

Koenig, A., and M.C. Holbrook. 2000. Instruction strategies for children and youths with visual impairment. Vol. 2 of Foundations of education. 2nd ed. New York: AFB.

Lancioni, G.E., N.N. Singh, M.F. O’Reilly, J. Sigafoos, D. Oliva, L. Severini, A. Smaldone, and M. Tamma. 2007. Microswitch technology to promote adaptive responses and reduce mouthing in two children with multiple disabilities. Journal of Visual Impairment and Blindness 101, no. 10: 628-36.

Lussenhop, K., and A.L. Corn. 2002. Comparative studies of reading performance of students with low vision. RE:view 34, no. 2: 57-69. 
Mason, H. 1999. Blurred vision: A study of the use of low vision aids by visually impaired secondary school pupils. British Journal of Visual Impairment 17, no. 3: 94-7.

Mason, H., S. McCall, C. Arter, M. McLinden, and J. Stone, Eds. 1997. Visual impairment: Access to education for children and young people. London: David Fulton Publishers.

McLeish, E. 2007. A study of the effect of letter spacing on the reading speed of young readers with low vision. British Journal of Visual Impairment 25, no. 2: 133-43.

Miller, O., S. Keil, and R. Cobb. 2005. Review of the literature on accessible curricula, qualifications and assessment. Report submitted to the Disability Rights Commission.

Mioduser, D., O. Lahav, and R. Nachmais. 2000. Using computers to teach remedial spelling to a student with low vision: A case study. Journal of Visual Impairment and Blindness 94, no. 1: 15-25.

Murphy, J.L., D. Hatton, and K. Erickson. 2008. Exploring the early literacy practices of teachers of infants, toddlers, and preschoolers with visual impairments. Journal of Visual Impairment and Blindness 102, no. 3: 133-46.

Nisbet, P. 2007. SQA adapted examination papers in digital format. 2007 pilot project report, Call Centre, University of Edinburgh.

Papadopoulos, K.S., and D.B. Goudiras. 2004. Visually impaired students and university examinations. British Journal of Visual Impairment 22, no. 2: 66-9.

Papadopoulos, K.S., and D.B. Goudiras. 2005. Accessibility assistance for visually impaired people in digital texts. British Journal of Visual Impairment 23, no. 2: 75-83.

Parsons, S., K. Guldberg, A. MacLeod, G. Jones, A. Prunty, and T. Balfe. 2009. International review of the literature of evidence of best practice provision in the education of persons with autistic spectrum disorders. National Council for Special Education, Ireland. http:// www.ncse.ie/uploads/1/Autism_Report.pdf

Russell-Minda, E., J.W. Jutai, J.G. Strong, K.A. Campbell, D. Gold, L. Pretty, and L. Wilmot, 2007. The legibility of typefaces for readers with low vision: A research review. Journal of Visual Impairment \& Blindness 101, no. 7: 402-15.

Sales, A., S. Evans, N. Musgrove, and R. Homfray. 2006. Full-screen magnification on a budget: using a hardware-based multi-dispoay graphics card as a screen magnifier. The British Journal of Visual Impairment 24, no. 3: 135-40.

Schweigert, P., and C. Rowland. 1992. Early communication and microtechnology: Instructional sequence and case studies of children with severe multiple disabilities. AAC: Augmentative and Alternative Communication 8, no. 4: 273-86.

Smith, J.K., and J.N. Erin. 2002. The effects of practice with prescribed reading glasses on students with low vision. Journal of Visual Impairment and Blindness 96, no. 11: 765-82.

Trief, E., and R. Feeney. 2003. Guidelines for a precollege curriculum for students with blindness and visual impairments. RE:view 35, no. 3: 137-43.

UNESCO. 1994. The Salamanca statement and framework for action on special needs education. Paris, France: UNESCO. 